\title{
Early Cholecystectomy Versus Late Cholecystectomy in Choledocholithiasis following Endoscopic Retrograde Cholangiopancreaticography
}

\author{
Pranav Sharma ${ }^{1}$, Varun Dogra² ${ }^{2}$ Ashish Rathore ${ }^{3}$ \\ 1Junior Resident, Department of Surgery, GMC, Jammu, Jammu and Kashmir, India. ${ }^{2}$ Senior Resident, Department of \\ Surgery, GMC, Jammu, Jammu and Kashmir, India. ${ }^{3}$ Junior Resident, Department of Surgery, GMC, Jammu, \\ Jammu and Kashmir, India.
}

\section{ABSTRACT}

\section{BACKGROUND}

It is hypothesized that early planned laparoscopic cholecystectomy after endoscopic sphincterotomy prevents recurrent biliary complications and reduces operative morbidity and hospital stay. The aim of our study is to look for advantages of early cholecystectomy over late laparoscopic cholecystectomy in post ERCP patients at Government Medical College, Jammu.

\section{METHODS}

This is a prospective study conducted at Department of Surgery at Government Medical College and Hospital, Jammu from January 2018 to December 2018. All the patients who underwent laparoscopic cholecystectomies after ERCP for CBD calculi were included in study and were categorized into two groups according to time interval between ERCP and Laparoscopic Cholecystectomy. Outcomes were compared on the basis of operating time, conversion to open cholecystectomy, intra op bleeding requiring transfusion, and hospital stay and post op complications such as infection, CBD injury, pancreatitis.

\section{RESULTS}

Thirty patients were included in this study, who presented with the features suggestive of cholelithiasis with choledocholithiasis. Of those, 19 were subjected to early laparoscopic cholecystectomy following ERCP and 11 were subjected to late laparoscopic cholecystectomy. A comparative study was performed which showed that a shorter interval is associated with lesser conversion rate, lesser postoperative blood transfusion, lesser wound infections with less operating time which is a surrogate marker for lesser intraoperative adhesions and other complications. Shorter interval is also associated with decreased hospital stay which depicts lesser burden on hospital resources and on mean expenses.

\section{CONCLUSIONS}

Short interval between endoscopic retrograde cholangiopancreatography and laparoscopic cholecystectomy is safe and effective method of treating cholelithiasis associated with choledocholithiasis. However, a larger sample size must be studied for a longer period of time to confirm the findings of this study.

\section{KEY WORDS}

Choledocholithiasis, Endoscopic Retrograde Cholangiopancreatography, Laparoscopic Cholecystectomy.
Corresponding Author:

Dr. Varun Dogra,

Department of Surgery,

Government Medical College,

Jammu-180001, Bakshi Nagar,

Jammu and Kashmir, India.

E-mail:drdogravarun@gmail.com

DOI: $10.14260 / \mathrm{jemds} / 2019 / 625$

Financial or Other Competing Interests: None.

How to Cite This Article:

Sharma P, Dogra V, Rathore A. Early cholecystectomy versus late cholecystectomy in choledocholithiasis following endoscopic retrograde cholangiopancreaticography. J. Evolution Med. Dent. Sci. 2019;8(38):2876-2880, DOI: $10.14260 /$ jemds/2019/625

Submission 12-07-2019,

Peer Review 05-09-2019,

Acceptance 11-09-2019,

Published 23-09-2019. 


\section{BACKGROUND}

Gallstones have been recognised since antiquity and have been found during autopsies of Egyptian mummies. Following the first successful open cholecystectomy in 1882, it was Eric Muhe, a German surgeon, who performed the first laparoscopic cholecystectomy (Lapara, the flank; and skopein, to examine) in 1985. Gallstone disease clearly results from a complex interaction of genetic and environmental factors. This is confirmed by an altered incidence of gallstone detection in people from diverse geographical areas with a different dietary regimen, level of physical activity and hygiene. The common mechanism of gallstone formation includes cholesterol hypersecretion, alteration in intestinal bile salt, cholesterol absorption and gall bladder hypokinesia, which leads to bile cholesterol supersaturation and nucleation. ${ }^{1}$ Incidence of CBD stones in cases of cholelithiasis is around $3.4 \%-15 \%{ }^{2}$ Choledocholithiasis can either be primary or secondary. Secondary Choledocholithiasis being more common occurs due to stones originating in gallbladder and then migrating through cystic duct to CBD. These secondary bile stones are cholesterol stones in $75 \%$ and black pigment stones in $25 \%$ of patients.

Primary bile duct stones originate from within bile ducts and are more common in Asian populations. These stones have lower cholesterol content and higher bilirubin content as compared with secondary stones. These stones are associated with biliary stasis and bacteria. ${ }^{3}$

The diagnosis of choledocholithiasis is initially suggested by symptomatology, laboratory tests, and ultrasound (US) findings. Individually, each of these variables has a poor sensitivity and specificity for choledocholithiasis. Abdominal ultrasound being the most commonly used initial diagnostic tool for suspected biliary stones has a sensitivity of 25-60\% and specificity of 95-100\%. ${ }^{4}$ Ultrasound can reliably detect a dilated extrahepatic bile duct, typically a CBD $>6 \mathrm{~mm}$. However, a large study of patients undergoing cholecystectomy found that nearly half of the patients with choledocholithiasis have a nondilated CBD. ${ }^{5}$ Moreover, the diameter of the extrahepatic bile duct increases with age and older patients may have a normal duct greater than $6 \mathrm{~mm}$. Largely, due to its poor sensitivity, a negative US does not rule out choledocholithiasis.

Contrast enhanced computed tomography has a sensitivity of $71-85 \%$ and specificity of $88-95 \%$ which can further be improved by addition of a hepatobiliary-excreted intravenous contrast agent.6,7 Since the introduction in 1991, Magnetic resonance cholangiopancreatography (MRCP) has emerged as an accurate, non-invasive diagnostic modality for investigating the biliary and pancreatic ducts with sensitivity of $90-100 \%$ and specificity of $92-100 \% .^{8,9}$ An impacted biliary stone will appear as a filling defect with a crescent of bile. ${ }^{10}$

In 1968, ERCP was introduced as a diagnostic tool in the management of biliary and pancreatic diseases. ${ }^{11}$ With introduction of Endoscopic sphincterotomy, ERCP has now developed as a therapeutic tool with sensitivity of $90 \%$ and specificity of $98 \% .^{12}$ ERCP stone extraction is successful $80 \%$ - $90 \%$ of time using the techniques of sphincterotomy and balloon catheter or Dormia basket stone retrieval.13 Pancreatitis is the most common complication seen after ERCP. ERCP- induced pancreatitis is defined as new or worsened abdominal pain with serum amylase that is greater than three times the upper limit of normal at 24 hours post procedure and requires at least two days of hospitalisation. Although transient elevation of pancreatic enzymes i.e. serum amylase and serum lipase is evident after ERCP. ${ }^{14}$ Long term complications include papillary stenosis, cholangitis and recurrent choledocholithiasis. ${ }^{15}$

The introduction of Laparoscopic cholecystectomy has significantly influenced the treatment of patients with gallstones. Currently it is estimated that over $80 \%$ of cholecystectomies are performed using the laparoscopic approach. Advantages of laparoscopic cholecystectomy include earlier bowel function, less postoperative pain, improved cosmesis, shorter length of hospital stay, earlier return to full activity and decreased overall cost. Laparoscopic cholecystectomy (LC) preceded by preoperative ERCP remains the cornerstone and most commonly practiced strategy worldwide for the management of coexisting gallbladder and CBD stones. ${ }^{16}$ According to the literature, the conversion rate for laparoscopic cholecystectomy (LC) after endoscopic sphincterotomy (ES) for choledocholithiasis reaches 20\%, when laparoscopic cholecystectomy is performed 6 to 8 weeks afterward ${ }^{3}$. Also, many Patients waiting to undergo cholecystectomy after ES for CBD stones, experiences recurrent biliary events requiring repeated endoscopic reintervention, emergency cholecystectomy or both which not only have an obvious influence on a patient's well-being, but also appear to be associated with increased difficulty of surgery and a more complicated postoperative course. ${ }^{17}$

It is hypothesized that early planned laparoscopic cholecystectomy after endoscopic sphincterotomy prevents recurrent biliary complications and reduces operative morbidity and hospital stay. The aim of our study is to look for advantages of early cholecystectomy over late laparoscopic cholecystectomy.

\section{METHODS}

This is a prospective study conducted at Department of Surgery at Government Medical College and Hospital, Jammu from January 2018 to December 2018. All the patients who underwent laparoscopic cholecystectomies after ERCP for CBD stones were included in this study. Patients with Carcinoma Gall bladder, Common bile duct strictures, Post ERCP pancreatitis, Associated Comorbidities (With contraindication to anaesthesia), Coagulopathy, End stage liver disease, previous upper abdominal surgeries were excluded from this study. Standard Four port Laparoscopic Cholecystectomy was performed after ERCP in patients with Cholelithiasis with CBD stones. Patients were categorised into two categories according to the interval after ERCP. Patients in Category A were subjected to early Laparoscopic Cholecystectomy within 3 days of ERCP, while patients in category B were subjected to late Laparoscopic Cholecystectomy after 3 days of ERCP. All base line investigations were done prior to study including CBC, RFT, LFT, Electrolytes, S. amylase, Fasting blood Sugar, Blood grouping, coagulation profile, serology etc. Various imaging studies were done including CXR, USG, CT (if needed), MRCP (In case USG is inconclusive). Outcomes were compared on 
the basis of Operating time, Conversion to open cholecystectomy, Intra op bleeding requiring transfusion, Hospital stay and Post op complications such as Infection, CBD injury, Pancreatitis.

\section{Statistical Analysis}

The results are presented in mean +_standard deviation for the quantitative variables and percentages for qualitative variables. The student $t$ test was used to compare normally distributed variables between the two groups. Proportions of patient characteristics, complication rates, and operative data of the two groups were compared using Chi- square test and Fischer's exact test. The $\mathrm{p}$ value $<0.05$ was considered statistically significant. All the analysis was carried out using SPSS 16. 0 version (SPSS Inc, Chicago, IL, USA).

\section{RESULTS}

This study has been conducted in Government Medical College and Hospital, Jammu w.e.f. 01-01-18 to 31-12-2018. Thirty patients were included in this study, who presented with the features suggestive of cholelithiasis with choledocholithiasis. Of those 19 were subjected to early laparoscopic cholecystectomy following ERCP and 11 were subjected to late laparoscopic cholecystectomy. A comparative study was performed.

\section{Age Distribution}

The patients ranged in age from 20 to 80 years. Maximum no. of patients in this study was in 4 th decade, $31.58 \%$ in group 1 and $27.27 \%$ in group 2 .

\begin{tabular}{|c|c|c|}
\hline \multirow{2}{*}{ Age (Years) } & \multicolumn{2}{|c|}{ Number of Patients (\%) } \\
\cline { 2 - 3 } & Group I (n=19) & Group II (n=11) \\
\hline$\leq 30$ & $3(15.79)$ & $1(9.09)$ \\
\hline $31-40$ & $6(31.58)$ & $3(27.27)$ \\
\hline $41-50$ & $3(15.79)$ & $1(9.09)$ \\
\hline $51-60$ & $5(26.32)$ & $4(36.36)$ \\
\hline$>60$ & $2(10.53)$ & $2(18.18)$ \\
\hline Mean Age \pm SD & $44.63 \pm 14.43$ & $501.09 \pm 14.35$ \\
\hline p-value & \multicolumn{2}{|c|}{0.112} \\
\hline \multicolumn{3}{|c|}{ Table 1. Age Distribution } \\
\hline
\end{tabular}

\section{Gender Distribution}

The patients were divided into two groups: group 1 which consisted of 7 males (36.84\%) and 12 females (63.16\%) whereas group 2 consisted of 4 males (36.36\%) and 7 females (63.64\%).The $p$ value for this data was 0.201 showing no bias according to distribution in the abovementioned.

\section{Duration of Surgery}

The average time taken for laparoscopic cholecystectomy in group 1 came out to be $48.68 \pm 15.44 \mathrm{~min}$ and the average time taken in case of group 2 was $69.18 \pm 11.46$ min. p value on comparison came out to be 0.001 .

\begin{tabular}{|c|c|c|}
\hline \multirow{2}{*}{$\begin{array}{c}\text { Duration of Surgery } \\
\text { (Min.) }\end{array}$} & \multicolumn{2}{|c|}{ Mean \pm Standard Deviation } \\
\cline { 2 - 3 } & Group I (n=19) & Group II (n=11) \\
\cline { 2 - 3 } & $48.68 \pm 15.44$ & $69.18 \pm 11.46$ \\
\hline p-value & \multicolumn{2}{|c|}{0.001} \\
\hline \multicolumn{2}{|c|}{ Table 2. Group Comparison for Duration of Surgery } \\
\hline
\end{tabular}

\section{Complications}

Blood transfusion was not required in group 1 while 4 patients $(36.36 \%)$ required blood transfusion in group 2 . There was no post op infection, CBD injury or post op pancreatitis in group 1 while there were 2 post op infections in group 2 and no CBD injury or post op pancreatitis. P value in both cases came out to be $<0.0001$ which is highly significant.

\begin{tabular}{|c|c|c|c|c|c|}
\hline \multirow{3}{*}{ Variables } & \multicolumn{4}{|c|}{ Number of patients (\%) } & \multirow{3}{*}{ p-Value } \\
\hline & \multicolumn{2}{|c|}{ Group I (n=19) } & \multicolumn{2}{|c|}{ Group II (n=11) } & \\
\hline & No & Yes & No & Yes & \\
\hline Blood transfusion & $19(100.00)$ & $0(0.00)$ & $7(63.64)$ & $4(36.36)$ & $<0.0001$ \\
\hline Post-operative infection & $19(100.00)$ & $0(0.00)$ & $9(81.82)$ & $2(18.18)$ & $<0.0001$ \\
\hline CBD injury & $19(100.00)$ & $0(0.00)$ & $11(100.00)$ & $0(0.00)$ & - \\
\hline Post-operative pancreatitis & $19(100.00)$ & $0(0.00)$ & $11(100.00)$ & $0(0.00)$ & - \\
\hline \multicolumn{6}{|c|}{$\begin{array}{l}\text { Table 3. Group Comparison for Blood Transfusion, Post-Operative } \\
\text { Infection, CBD Injury and Post-Operative Pancreatitis }\end{array}$} \\
\hline
\end{tabular}

\section{Hospital Stay}

The mean hospital stay in cases of early laparoscopic cholecystectomy was $6.32 \pm 1.67$ days while in cases of late laparoscopic cholecystectomy was $10.27 \pm 3.13$ days. P value in this comparison came out to be $<0.0001$.

\begin{tabular}{|c|c|c|}
\hline \multirow{2}{*}{ Hospital Stay (Days) } & \multicolumn{2}{|c|}{ Mean \pm Standard Deviation } \\
\cline { 2 - 3 } & Group I (n=19) & Group II (n=11) \\
\cline { 2 - 3 } & $6.32 \pm 1.67$ & $10.27 \pm 3.13$ \\
\hline p-Value & \multicolumn{2}{|c|}{$<0.0001$} \\
\hline Table 4. Group Comparison for Hospital Stay \\
\hline
\end{tabular}

\section{Conversion Rate}

Only 1 patient was converted to open cholecystectomy in case of early laparoscopic cholecystectomy (5.26\%) while 4 patients were converted in case of group 2 (36.36\%).

\begin{tabular}{|c|c|c|}
\hline \multirow{2}{*}{ Conversion Rate } & \multicolumn{2}{|c|}{ Number of Patients (\%) } \\
\cline { 2 - 3 } & Group I (n=19) & Group II (n=11) \\
\cline { 2 - 3 } p-Value & $1(5.26)$ & $4(36.36)$ \\
\hline \multicolumn{2}{|c|}{$<0.0001$} \\
\hline \multicolumn{2}{|c|}{ Table 5. Group Comparison for Conversion Rate } \\
\hline
\end{tabular}

\section{DISCUSSION}

Since the 1990s the management of biliary lithiasis has changed radically with introduction of laparoscopic cholecystectomy, intraoperative cholangiography and laparoscopic CBD exploration. In the present scenario, Laparoscopic cholecystectomy (LC) preceded by ERCP remains the cornerstone and is most commonly practiced strategy worldwide for management of co-existing gallbladder and CBD stones. However, timing between laparoscopic cholecystectomy after ERCP is still the matter of debate. Various parameters have been measured to assess the difficulty of surgery and morbidities associated if laparoscopic cholecystectomy after ERCP is done within 72 hrs. versus laparoscopic cholecystectomy done after $72 \mathrm{hrs}$. of ERCP.

In this study, we compared two groups: group I in which laparoscopic cholecystectomy (LC) was done within $72 \mathrm{hrs}$. of endoscopic retrograde cholangiopancreatography (ERCP) and group II included patients who underwent LC after 72 hrs. of ERCP. We compared these groups on the basis of 
duration of surgery, operative time, conversion rate to open cholecystectomy, length of hospital-stay and post-operative complications. In our study, mean operating time was longer in patients who underwent delayed cholecystectomy, possibly due to omental and bowel adhesions, scarring and fibrosis of biliary tree and Calot's triangle which makes the surgeon very cautious during dissection of the junction between cystic duct, common hepatic duct and CBD. Authors such as Ghnnam et al, ${ }^{18}$ Elmeguid SAA et al, ${ }^{19}$ Gorla et al ${ }^{20}$ in their study also compared duration of surgery as the primary outcome, which was similar to our study. Previous studies as done by Reinders JSK et al, ${ }^{21}$ Sahoo $\mathrm{R}$ et al, ${ }^{2}$ Bostanci EB et $\mathrm{al}^{22}$ have shown that LC after ERCP is more difficult than LC for uncomplicated cholelithiasis: the conversion rate of 8 to $55 \%$ has been seen in complicated cholelithiasis versus lower than $5 \%$ in case of uncomplicated cholelithiasis. In our study, higher conversion rate was seen when LC was done beyond 72 hrs. Only 1 patient (5.26\%) was converted to open cholecystectomy in group I (LC within $72 \mathrm{hrs}$. of ERCP) while 4 patients (36.36\%) were converted to open cholecystectomy in group II (LC after 72 hrs. of ERCP) giving a p value of $<0.0001$. It has been hypothesized that higher conversion rates in group II is due to the dense adhesions and intra-op bleeding. In our study, the mean hospital-stay in group I was $6.32 \pm 1.67$ days while in group II was $10.27 \pm 3.13$ days, $p$ value on comparing groups came out to be $<0.0001$, revealing that there was a significant difference between hospital stay of group I and group II. Mean hospital stay can be predicted based on the increased incidence drain placement, postoperative complications like surgical site infection. After ERCP, incidence of bactobilia increases over time thus leading to biliary related complications like acute pancreatitis, cholecystitis, cholangitis and high rate of infections for which the patients had to encounter a longer hospital stay. In our study, no blood transfusion was required in group I (Early LC post ERCP) as compared to $4(36.36 \%)$ in group II (late LC after ERCP) with significant $\mathrm{p}$ value $<0.0001$. There were 2 wound infections $(18.18 \%)$ in group II while there was no wound infection in group I. However, there was no CBD injury or post-operative pancreatitis.

\section{CONCLUSIONS}

Shorter interval is associated with lower conversion rate, fewer post-operative blood transfusions, fewer wound infections with less operating time which is a surrogate marker for lesser intraoperative adhesions and other complications. Shorter interval is also associated with decreased hospital stay which depicts lower burden on hospital resources and on mean expenses. Longer interval is associated with recurrent symptoms, more intraoperative complications, more hospital stay, depicting a higher mean expense and a greater burden on health services. Short interval between endoscopic retrograde cholangiopancreatography and laparoscopic cholecystectomy is safe and effective method of treating cholelithiasis associated with choledocholithiasis. However, this study is limited by a small sample size and short duration. However, a larger sample size must be studied for a longer period of time to confirm the findings of this study.

\section{REFERENCES}

[1] Corradini SG, Elisei W, Giovannelli L, et al. Impaired human gallbladder lipid absorption in cholesterol gallstone disease and its effect on cholesterol solubility in bile. Gastroenterology 2000;118(5):912-20.

[2] Sahu D, Mathew MJ, Reddy PK. Outcome in patients undergoing laparoscopic cholecystectomy following ERCP: Does timing of surgery really matter? Journal of Minimally Invasive Surgical Sciences 2015;4(1):e25226.

[3] Ko CW, Lee SP. Epidemiology and natural history of common bile duct stones and prediction of disease. Gastrointest Endosc 2002;56(Suppl 6):S165-9.

[4] Sugiyama M, Atomi Y. Endoscopic ultrasonography for diagnosing choledocholithiasis: a prospective comparative study with ultrasonography and computed tomography. Gastrointest Endosc 1997;45(2):143-6.

[5] Hunt DR. Common bile duct stones in non-dilated bile ducts? An ultrasound study. Australias Radiol 1996;40(3):221-2.

[6] Mark DH, Flamm CR, Aronson N. Evidence based assessment of diagnostic modalities for common bile duct stones. Gastrointes Endosc 2002;56(Suppl 6):S190S4.

[7] Gibson RN, Vincent JM, Speer T, et al. Accuracy of computed tomographic intravenous cholangiography (CT-IVC) with iotroxate in the detection of choledocholithiasis. Eur Radiol 2005;15(8):1634-42.

[8] Hallal AH, Amortegui JD, Jeroukhimov IM, et al. Magnetic resonance cholangiopancreatography accurately detects common bile duct stones in resolving gallstone pancreatitis. J Am Coll Surg 2005;200(6):869-75.

[9] Fulcher AS. MRCP and ERCP in the diagnosis of common bile duct stones. Gastrointest Endosc 2002;56(Suppl 6):S178-S82.

[10] Vitellas KM, Keogan MT, Spritzer CE, et al. MR cholangiopancreatography of bile and pancreatic duct abnormalities with emphasis on the single-shot fast spinecho technique. Radiographics 2000;20(4):939-57.

[11] Mallery JS, Baron TH, Dominitz JA et al. Complications of ERCP. Gastrointest Endosc 2003;57(6):633-8.

[12] Carr-Locke DL. The therapeutic role of ERCP in the management of suspected common bile duct stones. Gastrointest Endosc 2002;56(Suppl 6):S170-S4.

[13] Binmoeller KF, Schafer TW. Endoscopic management of bile duct stones. J Clin Gastroentrol 2001;32(2):106-18.

[14] Cotton PB, Lehman G, Vennes J, et al. Endoscopic sphincterotomy complications and their management: an attempt at consensus. Gastrointest Endosc 1991;37(3):383-93.

[15] Wojtun S, Gill J, Gietka W, et al. Endoscopic sphincterotomy for choledocholithiasis: a prospective single-centre study on the short-term and the long-term treatment results in 483 patients. Endoscopy 1997;29(4):258-65. 
[16] El-Nakeeb A, Ezzet H, Askar W, et al. Early versus late cholecystectomy after clearance of CBD stones by endoscopic retrograde cholangiopancreatography: a prospective randomized study. Surg Laparosc Endosc Percutan Tech 2016;26(3):202-7.

[17] Berggren U, Gordh T, Grama D, et al. Laparoscopic versus open cholecystectomy: hospitalization, sick leave, analgesia and trauma responses. Bt J Surg 1994;81(9):1362-5.

[18] Ghnnam WM. Early versus delayed laparoscopic cholecystectomy post ERCP. JSM Gen Surg: Cases \& Images 2016;1(2):1006.

[19] Elmeguid SAA, Elhameed HFA, Ali AEM, et al. Outcome of laparoscopic cholecystectomy following endoscopic retrograde cholangiopancreatography - Does time interval matter? Egy J Surgery 2013;32(4):261-5.
[20] Gorla GPR, Augustine AJ, Madhavan SM. Optimal timing of laparoscopic cholecystectomy after endoscopic retrograde cholangiopancreatography. Journal of Current Surgery 2014;4(2):35-9.

[21] Reinders JSK, Goud A, Timmer R, et al. Early laparoscopic cholecystectomy improves outcomes after endoscopic sphincterotomy for choledochocystolithiasis. Gastroenterology 2010;138(7):2315-20.

[22] Bostanci EB, Ercan M, Ozer I, et al. Timing of elective laparoscopic cholecystectomy after endoscopic retrograde cholangiopancreaticography with sphincterotomy: a prospective observational study of 308 patients. Langenbecks Arch Surg 2010;395(6):6616. 